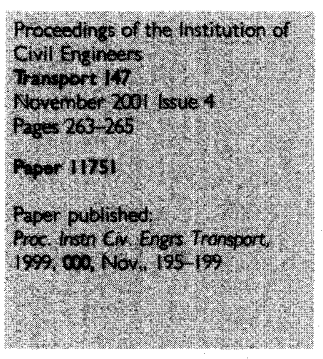

\title{
Predicted cost escalations in competitively bid highway projects
}

\section{T. P. Williams, J. C. Miles and C. J. Moore}

\section{P. G. O'Neil, Traffic Solutions Ltd}

The authors have demonstrated a potentially useful model for forecasting the out-turn cost of a highway project as a function of the lowest tender received and therefore of the scale of the project. Highway agencies would, however, be well-advised to exercise caution in disclosing any projects they may use because of the likelihood that contractors will perceive it as relatively more likely that claims will succeed so long as they do not breach the implied financial provision.

The causes identified for cost escalation lie largely in shortcomings in tendering and management, although the incidence of change orders and external events are acknowledged as other causes. Policing operations, as in some recent British highway projects, clearly fall into this last category, but surely the most consistent source of escalation is inadequate knowledge of ground conditions. Promoters are nowadays aware of the value of conducting extensive geological surveys, but these must always be incomplete, and some of the most spectacular cost overruns in recent years have occurred where even relatively short stretches of tunnel were involved. The London Jubilee Line extension is a case in point: given the huge and inevitable uncertainties in building an underground railway in a built-up river valley, the contractors and project managers are surely to be congratulated on the fact that overruns were not greater, rather than be subjected to ignorant press and political vilification.

\section{Author's reply}

The authors agree that shortcomings in tendering and management are a significant cause of the cost escalations that do occur. However, the causes of cost increases on individual projects are highly varied. The authors believe the model demonstrates that regardless of the cause of a cost increase, there is an underlying systematic cost escalation that occurs on the highway projects that is a function of the project scope.

\section{A. Farland,}

The above paper suggests that a simple relationship can be used to predict final construction costs using the low bid as input. I cannot reconcile the results that I obtain in applying equation (6) from paragraph 23 of the paper to the known facts on four major motorway schemes carried out in the UK between 1988 and 1991.
The tender values of the schemes were $£ 22$ million, $£ 27$ million, $£ 34$ million and $£ 53$ million. As I understand it, applying the equation would predict the final cost of these four schemes to be $45-46 \%$ over the tender cost. This was not the case-the final costs of the schemes were in fact $12 \%, 18 \%$ and $25 \%$ over tender.

There was also a National Audit Office report 'Department of Transport: Contracting for Roads' published in 1992 that indicated average cost increases for Department of Transport road contracts completed in the years 1988-1989 and 1990-91 to be $28 \%$.

\section{Author's reply}

Our main goal in writing this paper was to indicate that the completed cost and initial low bid can be simply related. We believe that it is of considerable interest that this relationship can be observed for highway projects in two countries.

The discussion to our paper describes how our model produced results for four highway schemes that were higher than the actual amount over tender using equation (6) from our paper. We believe that equation (6) should be used as an indicator of potential cost increases, and should not be regarded as a means of obtaining an exact number.

The deviation between the actual experience and the prediction obtained by our model probably occurred because of the relatively small sample of British Highways Agency cost data that we were able to obtain. We were only able to obtain data for 83 British Highways Agency projects constructed between 1990 and 1994. These cost data were in the public domain because they were compiled as a result of parliamentary questions. The completed project cost data are normally not available; therefore, our model is not based on a complete sample of all highway projects constructed by the British Highways Agency. We have assumed in our study that the sample of 83 projects represented a random sample of British Highways Agency projects. Our model has a high $R^{2}$ value, showing a good fit with the available data. Examination of the data indicates that it includes several large projects with very high cost escalations. Perhaps the projects we used to develop the model were more volatile than the total population of British Highway Agency projects. 
In conclusion, we believe that the models produced demonstrate a simple relationship between the low bid and final cost, that can be used to provide an indication of expected cost escalations. However, the small amount of data available to calculate the model for the British Highways Agency projects indicates that equation (6) should be used with some caution.

\section{K. J. Thomas,}

I found the paper by Williams, Moore and Miles interesting and potentially useful in cost control and forecasting on a generalised basis. The information is probably of more value in managing a portfolio of projects than in predicting out-turn for an individual scheme but nevertheless is an interesting piece of work.

One area that would be useful for further investigation would be to assess how close to the mean of the actual range of tenders the final outcomes were, even allowing some contingency. The acceptance of the lowest bid inevitably leads on a conventional contract to a search for a greater financial return, with the resulting cost escalation due in no small part to this.

Does the team have any data by which this could be assessed or any views on how close their predictions are likely to come to the mean or median of the tenders submitted?

\section{Author's reply}

It is possible that a measure of the central tendency of the submitted tenders for a product could give an indication of the completed project cost. The tender amounts are available for the highway projects constructed by the New Jersey Department of Transportation.

Three ratios can be calculated to measure how near the low, mean and median tenders are to the final project cost. The ratio of the mean tender amount to the final outcome, the ratio of the median tender amount to the final cost, and the ratio of the low bid to the final cost were calculated for 294 New Jersey projects. All of the projects studied had three or more tenders submitted.

A ratio value of 1 indicates that the value of the numerator (mean, median or low tender) exactly equalled the final project cost. Values greater then 1 indicate situations where the numerator value was greater then the final cost. Values less then 1 indicate situations where projects were completed for less than the numerator value.

The three ratio values are calculated for each of the $294 \mathrm{New}$ Jersey projects. Fig. 7 is a histogram that plots the frequency of observed values of the ratio of the mean of the submitted tenders to the completed project cost. The mean value of the ratio of mean tender to final cost is $1 \cdot 16$. Fig. 8 is the histogram for the ratio of the median tender to final cost. The mean value of the ratio of the median tender to final cost is $1 \cdot 13$. The observed values of the ratio of the low tender to final project cost are shown in the histogram in Fig. 9. The ratio using the low bid as numerator is $0 \cdot 97$. Examination of the histograms and these calculated means suggests that the mean and median of the tenders for the New Jersey projects tended to be higher then the completed project cost. For this data, it appears that the mean or median tenders are not good

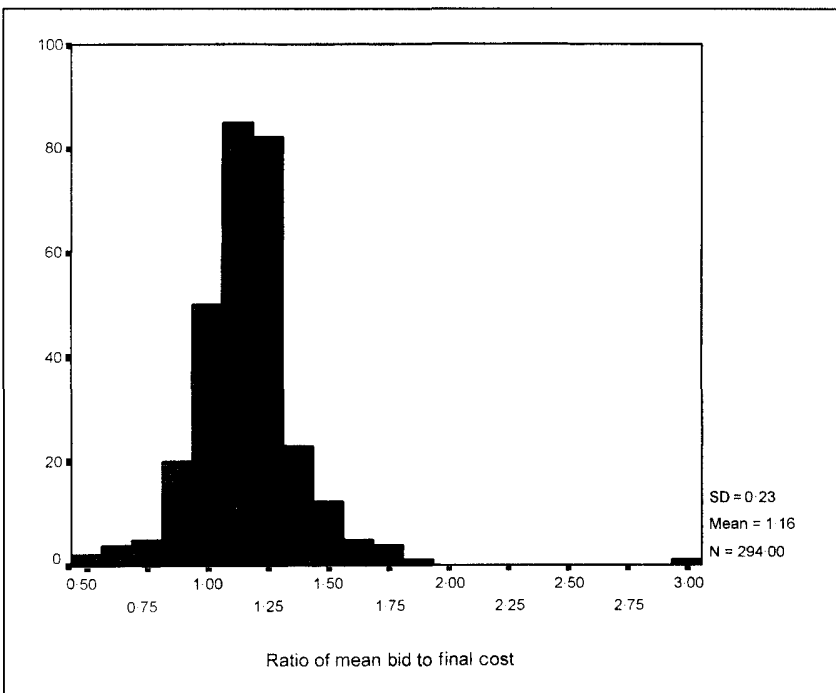

Fig. 7. Histogram of ratio of mean bid to final cost

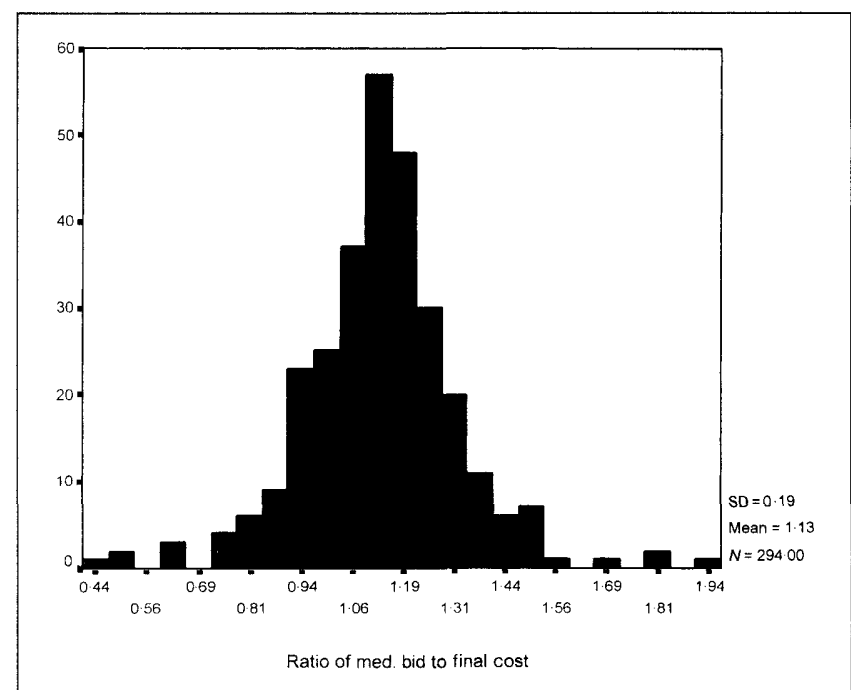

Fig. 8. Histogram of ratio of median bid to final cost

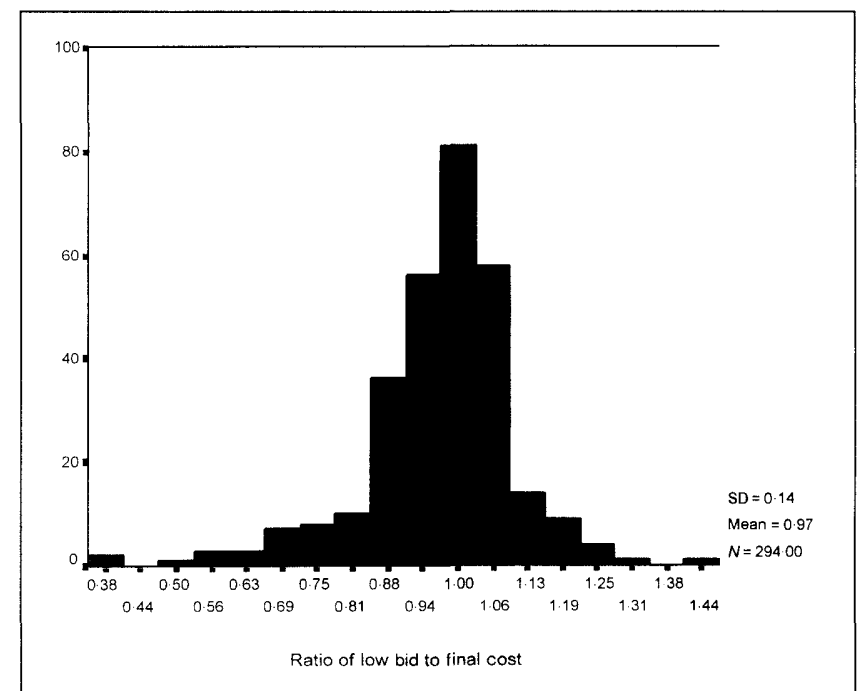

Fig. 9. Histogram of ratio of low bid to final cost 
indicators of the completed project cost. The low tender data tended to be closer to the completed project cost. Analysis of the data indicates that many of the projects had tenders significantly higher than the low tender, and ultimately much higher then the completed project cost.

As Thomas discussed, it would be expected that the low bidder would seek to escalate the price of the project to increase financial return. In this environment, it could then be expected that the mean of the tenders provides a better estimate of the actual project cost than the low bid. The reverse seems to be true for the New Jersey data. The low bids seem quite accurate, and the mean of the submitted tenders is often much higher then the final cost of the project. It would be useful to examine more bidding data to determine if this type of bidding pattern is observed in general or is local to New Jersey.

\section{P. Alexander}

Despite being impressed at the mathematical precision and analysis applied to the problem of cost overruns on highways projects, I find it surprising that the authors believe that such a predictive tool would be accepted by the clients (and consultants?) to whom it is directed. The assertion appears to be that we should be complacent when constructing 'traditional' re-measure contracts and accept that the out-turn cost will inevitably be greater than the tendered sum due to some preordained mathematical formula. Clients' advisers of any complexion would get very little thanks from their clients for telling them that according to a particular graph, the construction uncertainties and risks will add a certain percentage to the cost despite all of the advisers' efforts put into design, contract structure, etc.

Surely the right approach by a client's adviser is to recommend the appropriate form of contract to limit his exposure to additional costs, and to undertake a rigorous value engineering and risk assessment exercise to mitigate the costs associated with uncertainties.

Certainly on highways projects, the greatest risk lies below ground level due to the relatively greater physical footprint of the project compared with, say, a building, and it would perhaps have been valuable to break down into various categories the cost overruns on the highway projects studied so that a more accurate picture of where the overruns occur could be analysed. The tool could then possibly be used by bidding contractors who will recognise that the above-ground risks are much more containable and therefore priceable.

It may be that this predictive tool has, in any case, been overtaken by the recognition, at least in the UK, by the government agencies involved in highway promotion, that traditional re-measure contracts are not appropriate where certainty of outturn cost is important for budgetary purposes, since it seems that all future highway projects will be procured using either a 'design and build', or a 'design, build, finance and operate' form of contract. These forms allow the client to request a fixed price for construction, thus rendering the predictive tool redundant.

Author's reply

The main goal of this paper is to suggest that there is a repeatable relationship between the low bid and final cost. The purpose of this analysis is to shed light on the mechanism of cost increases for competitively bid projects. This research looked at data in a macroscopic way across many projects. We do not mean to suggest that the equations developed should replace a microscopic analysis of the details of an individual project, such as rigorous value engineering and risk assessment. The equations developed should be used as indicators coupled with judgement and knowledge about the individual project. 